\title{
OS MECANISMOS DE CONTROLE PROCESSUAL E O NOVO PANORAMA DO INCIDENTE DE RESOLUÇÃO DE DEMANDA REPETITIVA INSTALADO PELA LEI 13.105/2015
}

\section{THE CONTROL MECHANISM OF PROCEDURE AND THE NEW PANORAMA OF DEMAND REPETITIVE INSTALLED BY LAW RESOLUTION INCIDENT 13.105/2015}

Ana Luíza Zakur Ayres ${ }^{1}$

\section{RESUMO}

O estudo tem como objetivo tratar as inovações legislativas inseridas pela Lei 13.105/2015, especialmente no que tange ao Incidente de Resolução de Demanda Repetitiva, pois, será imprescindível aplicar dispositivos de forma dinâmica e aparelhada aos princípios. Será demonstrado como as ampliações e a verticalização de competência do Supremo Tribunal Federal, atribuíram temas como ponderação de valores com características persuasivas no dia- adia dos julgamentos. Assim, busca-se analisar o IRDR, sob uma ótica global, dado que objetiva definir tese jurídica comum a ações individuais repetitivas, a qual deverá ser adotada em todos os processos em que surja a mesma questão de direito.

Palavras-chave: Sistema político, Direito coletivo, Incidente de resolução de demanda (irdr), Estado democrático de direito, novo código de processo civil

\begin{abstract}
The study aims to address the legislative innovations inserted by Law $13.105 / 2015$, specially in relation to the incident Demand Resolution Repetitive therefore be necessary to apply dynamically devices and equipped principles. Will be shown to the expansion and vertical integration competence of the Supreme Court,assigned topics such as weighting values with enticing features in day- to-day trials. Thus, it seeks to analyze the IRDR,from a global perspective, as it aims to define common legal interpretation repetitive individual actions, which should be adopted in all cases in which it arises the same question of law.
\end{abstract}

Keywords: Political system, Collective law, Incident demand resolution repetitive (IRDR), Democratic state of law, New code of civil procedure

\footnotetext{
${ }^{1}$ Mestranda em Instituições Sociais, Direito e Democracia pela Fundação Mineira de Educação e Cultura Universidade FUMEC, Minas Gerais, (Brasil). Estagiária a nível de Pós Graduação na Promotoria do Meio Ambiente, (GEDEF - Grupo de Defesa da Fauna do Estado de Minas Gerais), (Brasil). E-mail: anazakur@gmail.com
} 


\section{INTRODUÇÃO}

A partir do novo Código de Processo Civil $^{2}$ não será mais possível aplicar dispositivos sem levar em consideração a dinâmica dos princípios. Há um especial tratamento atrelado ao modelo de Estado Democrático de Direito, na qual se percebe a importância do Direito estimulador de uma mudança radical, nesse novo contexto de legitimidade e necessidade de reconhecimento.

As transformações jurídico-sociais sofridas ao longo dos anos permitiram que as ações, antes puramente individuais, assumissem caráter mais coletivo ${ }^{3}$. No entanto, o Poder Judiciário passa por um longo período de crise, com inúmeras demandas semelhantes ajuizadas pelos mais diversos litigantes.

Por outro lado, especialmente o Supremo Tribunal Federal, no cenário sociopolítico atual, estão se tornando foco de atenção de uma nova geração de operadores do Direito, visto que temas como ponderação de valores, princípios ou moralidade, tornaram-se assuntos comuns, geralmente com características persuasivas no dia-a-dia dos julgamentos.

Contudo, as principais atribuições dos Tribunais Superiores deverá se adequar às diretrizes do processo democrático, de modo a evitar que as formas processuais sejam estruturadas e interpretadas em dissonância com os ditames do modelo constitucional de processo.

Outro ponto é o Incidente de Resolução de Demanda Repetitiva, que permite a provocação por decorrência de uma eventual simetria informacional com influência outorgada ao processo dentro de uma repetitividade no sentido da massificação, posto que a grande maioria dos litigantes são representados no polo passivo, ativo, parcial ou imparcial e objetivam alcançar exclusivamente resultados específicos, alcançados apenas mediante o processo judicial.

\footnotetext{
${ }^{2}$ Lei 13.105/2015, de 16 de Março de 2015. (2015,16 março). Institui o novo Código de Processo Civil. Diário Oficial da União.

3 PENEDO, Felipe Orletti. A progressão do ordenamento jurídico brasileiro no curso do Direito Transindividual: A criação do instituto de Resolução de Demandas Repetitivas. Disponível em <http://www.revistaalumni.com.br/index.php/ALUMNI/article/view/3〉. Acesso em 04 de nov. de 2015.
} 


\section{NOVA DIMENSÃo PRINCIPIOLÓGICA PREVISTA NA CONSTITUIÇÃO DA REPÚBLICA DE 1988}

O conceito de "acesso à Justiça" é custoso de definir, visto que sofreu e tem sofrido transformações importantes. Nos séculos dezoito e dezenove, o direito ao acesso à proteção judicial significava o direito formal do indivíduo de propor ou contestar uma ação. Àquela época, contemplava a filosofia essencialmente individualista ${ }^{4}$.

Já no sistema do "laissez faire", as diferenças entre litigantes em potencial no acesso à disponibilidade de recursos para litigar, não era preocupação do Estado ${ }^{5}$.

O conceito de direitos humanos transformou as sociedades do sistema "laissez faire", quando as ações e relacionamentos assumiram caráter mais coletivo, estampadas nas declarações de direitos confeccionadas à época.

$\mathrm{O}$ “acesso à justiça” passou a ser encarado como requisito fundamental, dos direitos humanos.

Sobre o assunto, André Del Negri ${ }^{6}$ explica:

\footnotetext{
"Essa importância ganhou novos traços com a Primeira Guerra Mundial (1914-1918), pois funcionou como divisor de águas entre o Estado Liberal e Estado Social (Welfare State). O primeiro, como visto, abstencionista; o segundo, socializante e paternalista, incentivado pela Encíclica Rerum Novarum do Papa Leão XIII a qual proclamou atenção ao lado social, refutando a idéia de capitalismo selvagem”.
}

Dada à promulgação das Constituições do México (1917) e Weimar (1919), questões de índole econômica passaram a ser reguladas constitucionalmente, sobrevindo um verdadeiro crescimento do modelo aplicado pelo Estado de Bem Estar Social em outros países ${ }^{7}$.

Preocupado em estimular o crescimento das atividades ligadas à saúde, educação, cultura, este novo modelo se aperfeiçoou por meio de um Estado intervencionista. O Judiciário passou a assumir papel central e o magistrado, nova responsabilidade de ser o "guardião" do Direito.

No Brasil, com a promulgação da Constituição da República de $1988^{8}$, foi trazida uma interessante proposta social de Modelo de Estado Constitucional. Em seu artigo $1^{\circ}$, a 
terminologia "Estado Democrático de Direito" é embasada em princípios, tais como: ampla defesa, contraditório, devido processo legal, que deve aparecer como uma espécie de qualidade, de característica, de paradigma jurídico:

Art. $1^{\circ}$ A República Federativa do Brasil, formada pela união indissolúvel dos Estados e Municípios e do Distrito Federal, constitui-se em Estado Democrático de Direito e tem como fundamentos:

I - a soberania; II - a cidadania;

III - a dignidade da pessoa humana;

IV - os valores sociais do trabalho e da livre iniciativa;

V - o pluralismo político. Parágrafo único. Todo o poder emana do povo, que o exerce por meio de representantes eleitos ou diretamente, nos termos desta Constituição.

Nos dias atuais, a sociedade brasileira repercute uma litigiosidade massificada, com inúmeras demandas semelhantes ajuizadas pelos mais diversos litigantes.

Muito embora, o processo civil brasileiro tenha tido, ao longo dos anos, várias reformas, com destaque para o vigente art.543- $\mathrm{C}^{9}$, o iter-procedimental encontra-se ainda adstrito à sua concepção original, de um processo individual, o que evidencia a necessidade, hoje realidade, da promulgação de um novo CPC que tenha como pilar o ideal de processo mais célere e coletivo.

Para uma percepção dos efeitos processuais dos litígios, devemos ter em conta dois fenômenos decorrentes da sociedade de massas: (i) a massificação de relações jurídicas materiais; e (ii) a massificação das relações jurídicas processuais.

\footnotetext{
${ }^{4}$ FALEIROS, Thaísa Haber. Tutela judicial efetiva como direito. Revista Jus Navigandi, Teresina, ano 7, n. 54, 1 fev. 2002. Disponível em:<http://jus.com.br/artigos/2682>. Acesso em: 4 nov. 2015.

${ }^{5}$ DEL NEGRI, André . Controle de Constitucionalidade no Processo Legislativo (2 $2^{\mathrm{a}}$ edição). $2^{\mathrm{a}}$. ed. Belo Horizonte: Editora Fórum, 2008. v. 1. p.34-35.

${ }^{6}$ Ibidem. p.37.

${ }^{7}$ Ibidem. p.39.

${ }^{8}$ BRASIL. Constituição (1988). Constituição da República Federativa do Brasil. Brasília, DF: Senado, 1988.

${ }^{9}$ BRASIL. Lei 5.869, de 11 de janeiro de 1973. Institui o Código de Processo Civil. Diário Oficial da União, Brasília, 17 jan. 1973.
} 
Nesta perspectiva, nasce à necessidade de se analisar o rumo que o litígio assume durante seu iter-procedimental, visto que o trajeto que percorre evidencia diversas características do conflito no cenário cultural, econômico, social, dentre outros.

O reconhecimento da necessidade de trato coletivo de demandas originadas de certas relações jurídicas reporta-se ao artigo de Mauro Cappelletti intitulado "Formações Sociais e Interesses Coletivos Diante da Justiça Civil"10.

Tanto o referido artigo quanto à pesquisa, "Acesso à Justiça",11, coordenada pelo jurista italiano em companhia do professor Bryant Garth, vieram exercer forte inspiração ao legislador, visto que no Brasil, vive-se um contexto marcado por demandas de massa, em que um número cada vez maior de pessoas procura o Judiciário na tentativa de pacificar conflitos.

O professor Marc Galanter ${ }^{12}$ possui uma visão distinta da causa das demandas repetitivas. Distingue os tipos de litigantes entre eventuais (One Shotter) e repetitivos (Repeat Players), bem como a atuação de cada um nos conflito, levando em conta interesses, benefícios e facilidades processuais.

O enfrentamento dessa problemática constitui-se em um dos objetivos precípuos de alguns dos institutos introduzidos no Projeto do Novo CPC, que atribuem maior importância ao precedente judicial, vislumbrado, agora, como um modelo orientador dos futuros pronunciamentos judiciais.

\section{AS PRINCIPAIS AMPLIAÇÕES E VERTICALIZAÇÃO DE COMPETÊNCIA DO SUPERIOR TRIBUNAL FEDERAL}

As principais mudanças processuais vivenciadas ao longo dos anos na tentativa de minimizar as ações individuais em trâmite no judiciário brasileiro foram:

\subsection{SÚMULAS VINCULANTES}

A jurisdição constitucional do Supremo Tribunal Federal reuniu influências tanto do modelo de controle de constitucionalidade concreto (descentralizado) norte-americano, como também do modelo abstrato (centralizado) de controle de constitucionalidade europeu. Apesar 
de existir efeito vinculante nas decisões de mérito analisadas sob o modelo abstrato de constitucionalidade desde $1993^{13}$, este não é encontrado no exame de constitucionalidade concreto o que fez produzir ao longo dos anos um numeroso acervo de processos repetitivos.

A ideia de súmula vinculante foi concebida pelo então Ministro Victor Nunes Leal, com o propósito de informar os juízes e advogados sobre a interpretação por meio de pronunciamento do Supremo Tribunal Federal.

Somente em 2003, o Ministro Sepúlveda Pertence apresentou novas propostas e 113 novos verbetes de Súmulas de caráter persuasivo foram validadas. Após o ano de 2004, não houve publicação de novos verbetes, em razão do advento das Súmulas Vinculantes.

Por meio da Emenda Constitucional n.45, intitulada "Reforma Constitucional do Judiciário" foi introduzida a súmula vinculante no ordenamento jurídico brasileiro, que confere ao Supremo Tribunal Federal o poder de exercer a jurisdição constitucional concreta com efeito vinculante, ou seja, de caráter obrigatório ${ }^{14}$ tanto para os tribunais inferiores como também para a Administração Pública federal, estadual e municipal ${ }^{15}$.

Em razão da qualidade excepcional do efeito vinculante sobre as decisões judiciais em países de tradição da civil law, a Constituição brasileira exige a maioria de dois terços dos Ministros da Suprema Corte para aprovar, modificar ou anular a súmula vinculante através de um processo específico ${ }^{16}$.

\footnotetext{
${ }^{10}$ CAPPELLETTI, Mauro. Formações sociais e interesses coletivos diante da justiça civil. Revista de processo. Tradução de Nelson Renato Palaia Ribeiro de Campos, São Paulo, nº 5, 1977.

${ }^{11}$ Mauro e GARTH, Bryan. Acesso à justiça. Tradução de Ellen Gracie Northfleet. Porto Alegre: Sergio Antonio Fabris, 2002.

${ }^{12}$ AMARAL, Guilherme Rizzo. Efetividade, segurança, massificação e a proposta de um "incidente de resolução de demandas repetitivas". In. WAMBIER, Teresa Arruda Alvim (org). Revista de Processo, v. 36, n. 196. São Paulo: Editora Revista dos Tribunais, 2011, p. 249/250.

${ }^{13}$ Ver GAROUPA, Nuno. MALDONADO, Maria A. The Judiciary in Political Transitions: The Critical Role of U.S Constitucionalism in Latin America. Cardozo J. Int'l \& Comp L., v.19.n.3,July 2010,p.526.

${ }^{14}$ BRASIL. Constituição (1988). Constituição da República Federativa do Brasil. Brasília, DF: Senado, 1988..Art. $102 \S 2^{\circ}$.

${ }^{15}$ Ibidem.
} 
O Supremo Tribunal de ofício pode propor a edição de súmula vinculante ${ }^{17}$. Equitativamente, determinados membros do governo, bem como certos representantes da sociedade civil ${ }^{18}$. Ademais, durante os procedimentos, terceiros interessados podem expressar sua opinião sobre o tema na qualidade de amicus curiae ${ }^{19}$.

O acervo de processos acumulados na Corte, foi diminuindo ano a ano, em razão da criação dos impedimentos no intuito do não recebimento de recursos interpostos. Assim, foram resolvidas questões controversas que suscitavam grave insegurança e geravam muitos processo judiciais similares sobre a mesma questão ${ }^{20}$.

Diversamente da doutrina do "stare decisis" concebida pelo sistema norte-americano, que atribui todas as decisões da Suprema Corte dos Estados Unidos com estímulo de precedente obrigatório, o mecanismo brasileiro serve como instrumento apenas em relação a questões previamente selecionadas que deram origem a diversos processos repetitivos sobre a mesma temática ${ }^{21}$.

Como o pronunciamento ocorre abstratamente, a súmula vinculante, parece conferir a Corte uma abertura maior para decidir sobre supostas violações de seu conteúdo, posto que os magistrados não necessitam de examinar se os fatos do caso abordado sob sua jurisdição são distintos ou similares aos fatos analisados nos casos que originaram a súmula vinculante. Torna-se simples para um magistrado aplicar a súmula sem a exigência de se fazer uma detalhada análise dos fatos. Com efeito, esse sistema proporciona aos indíviduos acesso direto ao Supremo Tribunal Federal, em caso de violações a enunciado da súmula vinculante por órgãos do governo.

\footnotetext{
${ }^{16}$ Ibidem.

${ }^{17}$ Art. $2^{\circ}$ da Lei 11.417, de 19 de Dezembro de 2006. Diário Oficial da União, 20 dez. 2006.

${ }^{18}$ Art. $2^{\circ}$ e $3^{\circ}$ da Lei 11.417, de 19 de Dezembro de 2006. Diário Oficial da União, 20 dez. 2006.

${ }^{19}$ Ibidem.

${ }^{20}$ SILVA, J. Anchieta. A Súmula de efeito vinculante amplo no direito brasileiro. Belo Horizonte: Del Rey, 1998, p.60.

${ }^{21}$ Ibidem, nota 28, p.3.
} 


\subsection{SÚMULAS IMPEDITIVA DE RECURSO}

Visando mudar este quadro massificado de demandas repetidas, a preocupação dos legisladores, tornou-se expressa com a Emenda Constitucional no 45, promulgada em 2004 (EC 45/04), que positivou no ordenamento jurídico pátrio o direito ao acesso à jurisdição, com o objetivo de prestação jurisdicional eficiente e eficaz como garantia fundamental.

Devido a inúmeras avaliações feitas às súmulas de efeito vinculante, o legislador originário achou por bem propor, em lei ordinária, a súmula impeditiva de recurso.

A súmula impeditiva de recurso consiste na inadmissão e não conhecimento de recurso à instância superior caso já existam súmulas de jurisprudência dominante do STF e do STJ contrárias às ideias contidas nos recursos.

Tal instituto foi previsto no projeto de lei do Senado 140/2004, o qual foi promulgado em 08/02/2006, podendo ser considerado no plano processual civil como súmula vinculante de ordem constitucional. Tem o objetivo de trazer à primeira instância judiciária o poder anteriormente conferido ao relator do recurso de denegar o prosseguimento de recurso cuja matéria for pacífica e constante de súmula dos tribunais superiores.

Consiste, então, na inadmissão e não conhecimento de recursos à instância superior caso já existam súmulas e jurisprudências dominantes do Supremo Tribunal Federal (STF) e Superior Tribunal de Justiça (STJ), contrárias às ideias contidas nos recursos. Quando tais situações ocorrerem, o juiz recebedor do recurso poderá decidir a questão liminarmente. A súmula vinculante e a impeditiva de recursos pretendem resultados próximos, mas, apresentam métodos distintos.

Como já ressaltado, atualmente as súmulas do Supremo Tribunal Federal precisam ser ratificadas para ter a conferência do efeito vinculante. No entanto, para que uma súmula seja impeditiva de recursos esse procedimento não é necessário. Contudo, na prática, haverá uma vinculatividade da primeira instância às súmulas. 
É interessante ressaltar que não há previsão constitucional para a "vinculatividade" das súmulas expedidas pelo Tribunal Superior do Trabalho e Superior Tribunal de Justiça, embora ambos os tribunais tenham súmulas internas de aplicação interna administrativa. A lei 11.276/06 inovou em mais esse ponto restringindo como parâmetro cardeal para tais decisões liminares as jurisprudências das mais altas cortes do Brasil.

Ademais, com o acolhimento da súmula impeditiva de recursos, busca-se efetividade da súmula vinculante, conferindo-lhe celeridade na prestação jurisdicional através da aplicação imediata das decisões das mais altas cortes do país conforme observa o prof. Humberto Theodoro Júnior ${ }^{22}$ :

O raciocínio determinante da reforma foi no sentido de que, se admite que uma súmula vincule juízes e tribunais, impedindo-os de julgamento que a contrarie, válido é, também, impedir a parte de recorrer contra sentença proferida em consonância com o assentado em jurisprudência sumulada pelos dois mais altos tribunais do país. Nos dois casos está em jogo o mesmo valor, qual seja, o prestígio da 46 Súmula do STJ e do STF pela ordem jurídica.

Vale lembrar, como já mencionado, que o relator com base na jurisprudência reiterada do próprio tribunal ou com base em súmulas dos tribunais superiores poderia julgar de ofício a questão.

Desta maneira, por intermédio deste tipo de súmula, quando a sentença a qual se insurge a parte vencida estiver de acordo com súmula dos tribunais superiores, o juiz recebedor do recurso poderá decidir a questão liminarmente, sem sequer ouvir a parte contrária ou remeter à instância superior o recurso de apelação. Com mais essa mudança legislativa pretendeu-se conferir eficiência, eficácia e tempestividade na prestação jurisdicional.

\subsection{REPERCUSSÃO GERAL}

A inclusão do instituto da repercussão geral se deu pela Emenda Constitucional n ${ }^{o}$ 45/03, posteriormente regulamentada pela Lei 11.418/2006. Trata-se de pressuposto de admissibilidade do recurso extraordinário, pretendendo não somente limitar os feitos que são remetidos ao Supremo Tribunal Federal, como também promover um julgamento simplificado destes, a partir de controvérsias consideradas idênticas. 
Sua inserção no cenário jurídico brasileiro visou tornar cada vez mais célere os procedimentos, nos termos do inciso LXXIII, do art. $5^{\circ}$, da CR/88, também inserido pela EC 45/2003, diminuindo o volume de feitos que são remetidos e julgados nos tribunais superiores.

Acerca da definição de repercussão geral, é informação contida no endereço eletrônico do Supremo Tribunal Federal (www.stf.jus.br):

A Repercussão Geral é um instrumento processual inserido na Constituição Federal de 1988, por meio da Emenda Constitucional 45, conhecida como a "Reforma do Judiciário". O objetivo desta ferramenta é possibilitar que o Supremo Tribunal Federal selecione os Recursos Extraordinários que irá analisar, de acordo com critérios de relevância jurídica, política, social ou econômica. $\mathrm{O}$ uso desse filtro recursal resulta numa diminuição do número de processos encaminhados à Suprema Corte. Uma vez constatada a existência de repercussão geral, o STF analisa o mérito da questão e a decisão proveniente dessa análise será aplicada posteriormente pelas instâncias inferiores, em casos idênticos.

Para regulamentar o instituto da Repercussão Geral, foi promulgada a Lei 11.418/06 e acrescido os arts. 543-A e B no vigente Código de Processo Civil.

O conceito do que seja Repercussão Geral encontra-se definido no art. 543-A, $\S 1^{\circ}$, que impõe sua aplicação quando a controvérsia abranger "questões relevantes do ponto de vista econômico, político, social ou jurídico, que ultrapassem os interesses subjetivos da causa", devendo se ultrapassado o âmbito de interesse das partes.

Verifica-se que a Repercussão Geral é apreciada por meio de conceitos indeterminados, pois "abre-se ao aplicador da norma, como é intuitivo, certa margem de liberdade. Algo de subjetivo quase sempre haverá nessa operação concretizadora, sobretudo quando ela envolva, conforme com frequência, a formulação de juízo de valor ${ }^{23}$ ".

\footnotetext{
${ }^{22}$ THEODORO JÚNIOR, Humberto. Curso de direito processual civil. 39. ed. Rio de Janeiro: Forense, 2005.,3 v.,p.660.

${ }^{23}$ CASAGRANDE, Érico Vinícius Prado. Repercussão Geral no Recurso Extraordinário e Garantia Fundamental da Ampla Defesa: Estudo do novo requisito de admissibilidade do recurso extraordinário sob a perspectiva de uma teoria do direito democrático. 2008., p.115. Dissertação (Mestrado em Direito Processual) - Pontifícia Universidade Católica, Belo Horizonte.
} 
Destarte, verifica-se que o instituto da Repercussão Geral, muito embora tenha almejado a celeridade e efetividade do provimento jurisdicional pela instância superior e tenha pressupostos de fortalecimento, principalmente, do Superior Tribunal Federal (STF), atualmente, encontra-se em desarmonia com o modelo democrático coletivo-participativo, tendo em vista principalmente o fato de ser justificada por conceitos indeterminados, fazendo com que a Suprema Corte continue a decidir ilegitimadamente, necessitando, pois, de uma reanálise.

\section{BREVES REFLEXÕES ACERCA DO INCIDENTE DE RESOLUÇÃO DE DEMANDAS REPETITIVAS (IRDR)}

De acordo com as informações constantes do levantamento estatístico Justiça em Números 2013, confeccionado pelo Conselho Nacional de Justiça - CNJ e relativo aos dados do Poder Judiciário referentes ao exercício de 2012, o número de processos em trâmite no Judiciário cresceu 10,6\% nos últimos quatro anos e chegou a 92,2 milhões de ações em tramitação em $2012^{24}$.

Foi neste espírito que houve algumas tentativas de solução coletiva em diversos dispositivos da nossa legislação pátria, como ocorre no incidente de reserva de plenário (art.97 da CR/88 e art. 480 e ss. do CPC vigente ${ }^{25}$ ), e ainda o incidente de uniformização de jurisprudência, previsto no art.476 do CPC vigente.

Com o mesmo objetivo, os artigos 18 e 19 da Lei 12.153/2009 preveem o cabimento de pedido de uniformização da interpretação de lei nos Juizados Especiais da Fazenda Pública no âmbito dos Estados, do Distrito Federal, dos Territórios e Municípios, quando houver divergência entre decisões proferidas por Turmas Recursais sobre questões de direito material $^{26}$.

\footnotetext{
${ }^{24}$ BRASIL, Conselho Nacional de Justiça. Justiça em Números 2013. Brasília. Departamento de Pesquisas Judiciárias, 2013. Disponível em <http://www.cnj.jus.br/>

${ }^{25}$ Lei 5.869, de 11 de janeiro de 1973. Institui o Código de Processo Civil. Diário Oficial da União.

${ }^{26}$ CAVALCANTI, Marcos. Incidente de Resolução de Demanda Repetitiva e Ações Coletivas. Editora Juspodivm, 2015, p.411.
} 
Apesar de todas as medidas tomadas pelo legislador brasileiro para uma justiça mais célere e eficaz, e, também, em que pese o STF ter obtido expressiva redução de processos que lhe eram distribuídos anualmente, o cenário global de processos judiciais continua desfavorável ao Poder Judiciário ${ }^{27}$.

É preciso realizar uma análise crítica do novo instituto, haja vista o estudo realizado por Luiz Flávio Borges D' Urso ${ }^{28}$, atesta que:

[...] de cada 10 processos nas prateleiras do Judiciário, apenas três são julgados no ano, significando que a taxa de congestionamento da Justiça, em todos os ramos, é de $70 \%$. Quarenta e três milhões de processos aguardam julgamento pela Justiça de nosso país. Esses números assustadores demonstram a gravidade da crise a que está submetido o Poder Judiciário no Brasil.

Outro ponto de destaque diz respeito aos magistrados, pois segundo a pesquisa elaborada por Luiz Flávio Borges "hoje, contamos com um corpo de 15 mil juízes, o que significa um juiz para cada 30 mil habitantes, enquanto, por exemplo, na Alemanha, a proporção é de um juiz para cada 3 mil habitantes".

É fácil constatar a disseminação de demandas repetitivas, sem que haja instrumentos capazes de julgá-las conjuntamente, em observância não só ao princípio da efetiva prestação jurisdicional, mas também ao da segurança jurídica. Dessa forma, a crise do Judiciário passa a ser vislumbrada sob duas vertentes diversas, no caso, a vertente quantitativa, no que tange ao acúmulo de processos e ações sem um desfecho definitivo, e uma vertente qualitativa, uma vez que a alta demanda de processos impede que os magistrados exerçam sua atividade cognitiva com mais atenção e técnica, o que não raras vezes culmina em decisões com fundamentações limitadas e partes dispositivas conflitantes, embora os casos discutidos sejam juridicamente iguais ou equivalentes.

O desenvolvimento do incidente de resolução de demanda repetitiva devem conviver com os demais e não se sobrepor, por exemplo, às ações coletivas de formato representativo que possuem papel indispensável no cenário jurídico brasileiro.

27 CAVALCANTI, Marcos. Incidente de Resolução de Demanda Repetitiva e Ações Coletivas. Editora Juspodivm, 2015, p.411/412.

${ }^{28}$ D’URSO, Luiz Flavio Borges. A crise no Poder Judiciário. Disponível em: . Acesso em: 27 Jul.2015. 
No NCPC, este instituto deve ser visto com ponderação, pois além de corrigir eventual desigualdade entre as partes para a elucidação da tese jurídica, terá força vinculante aos julgamentos em casos repetitivos para futuras demandas judiciais.

\title{
5. O INCIDENTE DE RESOLUÇÃO DE DEMANDA REPETITIVA (IRDR) E O NOVO CÓDIGO DE PROCESSO CIVIL (LEI 13.105/2015)
}

O instituto brasileiro de Incidente de Resolução de Demandas Repetitivas, doravante denominado apenas IRDR, foi criado a partir de um instituto similar previsto no direito alemão (Kapitalanleger-Musterverfahrengesetz-KapMug).

Para melhor compreender a evolução histórica é preciso esclarecer que, de acordo com o art. 95 da Lei Fundamental (Grund-gesetz), o Poder Judiciário na Alemanha é dividido, em razão da matéria nas seguintes justiças: (a) Justiça Comum ou Ordinária, (b) Justiça do Trabalho, (c) Justiça das Finanças, (d) Justiça Administrativa e (e) Justiça Previdenciária ou Social $^{29}$.

A lei que inseriu o procedimento-modelo no sistema processual alemão foi editada em 2005. A princípio, possuía prazo de validade de cinco anos, todavia, a técnica foi incorporada a ZPO (Zivilprozessordnung). Técnica similar foi ampliada em 2008 na Alemanha, quando da ocorrência de mais de 20 casos idênticos envolvendo a assistência e previdência social $\left(\right.$ Sozialgerichtsgesetz) ${ }^{30}$.

O professor Dierle Nunes explica como nasceu a KapMug:

\begin{abstract}
"A origem da KapMuG diz respeito ao caso Deutsche Telekom (DT), empresa com mais de três milhões de acionistas na Alemanha. Em função de suposta veiculação de informações equivocadas a respeito da extensão do patrimônio da sociedade em duas circulares de ofertas de ações (em 1999 e 2000), milhares
\end{abstract}

\footnotetext{
${ }^{29}$ LEAL, Márcio Flávio Mafra. Curso de Processo Civil comparado Brasil-Alemanha. In: Revista de Processo. São Paulo: RT, n.178, dez. 2009, p.230.

${ }^{30}$ NUNES, Dierle José Coelho; THEODORO JR, Humberto; BAHIA, Alexandre G. M. F.; PEDRON, Flávio Quinaud. Novo CPC: Fundamentos e sistematização - Lei 13.015, de 16.03.2015. 2. ed. Rio de Janeiro: Gen/Forense, 2015. v. 1. p.381.
} 
de investidores ditos lesados (aproximadamente 15 mil), representados por mais de setecentos e cinquenta advogados diferentes, propuseram demandas contra a $D T$ perante a corte distrital de Frankfurt, foro da sede da bolsa de valores em que os prospectos circularam. O conjunto das ações representava valor superior a cento e cinquenta milhões de euros".

Alguns autores começaram a interpor recursos de constitucionalidade diretamente ao Tribunal Federal Constitucional Alemão $(B V e r f G)$, alegando violação à garantia da razoável duração ao processo. Embora, o BVerfG tenha negado provimento aos recursos, por entender que a lentidão processual era tolerável em razão das peculiaridades do caso concreto, recomendou-se que a Landesgericht de Frankfurt desse celeridade à resolução das aludidas demandas.

Em 2005, o legislador alemão, considerando a decisão proferida pelo Tribunal Federal Constitucional Alemão, editou a Lei de Introdução do Procedimento modelo para investidores em Mercado de Capitais (KAPMUG), prevendo o cabimento de um incidente de resolução coletiva de conflitos de massa no âmbito das controvérsias decorrentes do mercado mobiliário $^{31}$.

Em uma experiência, a intenção da aplicação do modelo tedesco, é estabelecer uma esfera de decisão coletiva de questões comuns a litígios individuais, sem esbarrar nos ataques teóricos e entraves práticos da disciplina das ações coletivas de tipo representativo, com espectro de abrangência subjetivo para além das partes. A finalidade é criar posicionamento sobre pressupostos fáticos ou jurídicos de pretensões repetitivas de alguns pontos litigiosos (Streitpunkte) - leiam-se elementos fáticos ou questões prévias, apontados pelo requerente na petição inicial, fazendo com que a decisão do magistrado atinja diversos litígios individuais ${ }^{32}$.

Apresentado no Brasil pelo professor Antônio do Passo Cabral, nos idos de $2007^{33}$, trata-se de uma inovação do novo $\mathrm{CPC}^{34}$ e está regulado no capítulo VIII, do livro III pelos

\footnotetext{
${ }^{31}$ NUNES, Dierle José Coelho; THEODORO JR, Humberto; BAHIA, Alexandre G. M. F. ; PEDRON, Flávio Quinaud . Novo CPC: Fundamentos e sistematização - Lei 13.015, de 16.03.2015. 2. ed. Rio de Janeiro: Gen/Forense, 2015. v. 1. p.378.

${ }^{32}$ CABRAL, Antonio do Passo. O novo Procedimento-Modelo (Musterverfahren) alemão: uma alternativa às ações coletivas. Revista de Processo, v. 147, p. 132, 2007.

33 CABRAL, Antonio do Passo. O novo Procedimento-Modelo (Musterverfahren) alemão: uma alternativa às ações coletivas. Revista de Processo, v. 147, p. 40-55, 2007.
} 
artigos 976 a 987, que trata dos processos nos tribunais e dos meios de impugnação das decisões judiciais.

Cuida-se de um procedimento no qual poderão se manifestar várias pessoas, com diversas teses relacionadas à matéria litigiosa, e, ao final, o tribunal competente fixará tese jurídica será aplicada obrigatoriamente a todas as ações individuais ou coletivas.

A proposta apresentada ao Senado Federal tem o potencial de um processo mais célere e justo, mais próximo das necessidades sociais, sendo muito menos complexo do que o CPC de 1973. Para a Comissão de Juristas, "a simplificação do sistema, além de proporcionar-lhe coesão mais visível, permite ao juiz centrar sua atenção, de modo mais intenso, no mérito da causa" 35 .

O artigo 976 do novo Código de Processo Civil prevê o cabimento do IRDR quando estiverem reunidos dois pressupostos. O inciso I prescreve a hipótese de haver legítima repetição de processos que contenham controvérsia sobre a mesma questão unicamente e o inciso II, a possibilidade de haver risco de ofensa à isonomia e à segurança jurídica, é possível instaurar o IRDR.

Importante ressaltar que, na redação da Câmara dos Deputados, foi retirada a possibilidade de instauração preventiva do instituto, ainda quando não houvesse qualquer debate mais elaborado no Poder Judiciário. ${ }^{36}$

Nota-se ainda que o artigo 976 não exige quantidade mínima de ações à ensejar a instauração do incidente, necessitando somente que se verifique a potencialidade de relevante multiplicação de litígios, implicando em um juízo genérico de demandas com caráter objetivo. Já incidente da Musterverfahren difere nesse aspecto, pois impõe ampla publicidade e a existência de outros nove processos que possuam a mesma questão de fato ou de direito do processo representativo ${ }^{37}$.

\footnotetext{
${ }^{34}$ Lei 13.105/2015, de 16 de Março de 2015. (2015,16 março). Institui o novo Código de Processo Civil. Diário Oficial da União.

${ }^{35}$ FUX, Luiz. [Presidente da Comissão de Juristas instituída pelo Ato do Presidente do Senado Federal n.379/2009] [et.al.]. Anteprojeto no novo Código de Processo Civil. Disponível em: http://www.senado.gov.br
} 
Trata-se de uma técnica introduzida com a finalidade de auxiliar no dimensionamento da litigiosidade repetitiva mediante uma cisão da cognição através do "procedimento-modelo" ou "procedimento-padrão", ou seja, um incidente no qual "são apreciadas somente questões comuns a todos os casos similares, deixando a decisão de cada caso concreto para o juízo do processo originário", que aplicará o padrão decisório em consonância com as peculiaridades fático-probatórias de cada caso concreto para o juízo do processo originário.

Deste modo, o artigo 977, prevê em seu caput e incisos que o incidente será dirigido ao presidente do tribunal pelo juiz, relator, por ofício, pelas partes, por petição, pelo Ministério Público ou pela Defensoria Pública, por petição, visto que o IRDR delimita a matéria jurídica (976, I). O parágrafo único acrescenta a necessidade de demonstração do preenchimento dos pressupostos para a instauração do incidente.

Observa-se que o que justifica sua propositura é a identificação de uma possibilidade de multiplicação de litígios que guardem entre si similaridades, sem, contudo, prever a obrigatoriedade do requerente apontar meios de prova que pretende produzir.

Neste sentido, o incidente alemão difere do proposto no Brasil, visto que não pode ser instaurado de ofício pelo Juízo $^{38}$, noutro ponto, exige expressamente a obrigatoriedade do requerente descrever os meios de provas que pretende produzir.

A previsão contida no art. 978 do NCPC prevê a obrigatoriedade da criação de um determinado órgão para o processamento e julgamento do incidente de resolução, sendo indispensável previsão no regimento interno da casa julgadora. Desta forma, os Tribunais terão a tarefa de atualizar seus regimentos internos, repensando na distribuição de competências de suas câmaras, bem como a natureza do novo órgão. O incidente tedesco da atribui a responsabilidade de julgamento de forma similar, visto que o Tribunal Regional (Oberlandesgericht), que decide o mérito (o objeto $)^{39}$.

\footnotetext{
${ }^{36}$ NUNES, Dierle José Coelho; THEODORO JR, Humberto ; BAHIA, Alexandre G. M. F. ; PEDRON, Flávio Quinaud . Novo CPC: Fundamentos e sistematização - Lei 13.015, de 16.03.2015. 2. ed. Rio de Janeiro: Gen/Forense, 2015. v. 1. p.379.

37 CABRAL, Antonio do Passo. O novo Procedimento-Modelo (Musterverfahren) alemão: uma alternativa às ações coletivas. Revista de Processo, v. 147, p. 132, 2007.

${ }^{38}$ Ibidem, p. 133.

${ }^{39}$ Ibidem, p. 133.
} 
A publicidade atribui maior dimensão ao a decisão do precedente, legitimando-o perante os jurisdicionados. A intenção de divulgação à sociedade encontra-se preconizada no art. 979 do NCPC. Para tanto, os incisos do citado artigo prevê que os Tribunais, com a comunicação imediata ao Conselho Nacional de Justiça terão a obrigação de manter banco de dados atualizados com informações específicas sobre questões de direito submetidas ao incidente, bem como fácil identificação dos processos abrangidos pela decisão. Ressalta-se que o incidente alemão trata-se a publicidade da mesma forma, de forma a otimizar a resolução das questões comuns e facilitar a consulta pública.

$\mathrm{O}$ art. 980, em seu turno, prescreve que o incidente será julgado no prazo de 1 (um) ano e terá preferência sobre os demais feitos. Previsão esta, que não existe no modelo alemão.

$\mathrm{O}$ art. 982 prescreve que o relator do processo suspenderá os processos pendentes, individuais ou coletivos, que tramitam no Estado ou na região, conforme o caso, bem como poderá requisitar informações ao juiz originário da causa, para que colha o maior número possível de informações e subsídios para se julgar uma causa que ultrapassa a esfera individual e ressoam em vários outros.

No que concerne à suspensão dos demais processos que versem sobre a mesma questão de direito, tem-se que o prazo será até que finde a apreciação dos requisitos de admissibilidade e do mérito, cessando tal suspensão se não for interposto recurso especial ou recurso extraordinário contra a decisão proferida no incidente. Na verificação dos requisitos de admissibilidade, o tribunal irá considerar a conveniência de se adotar uma decisão paradigmática, bem como observará se os requisitos previstos no art. 976 do novo CPC foram devidamente preenchidos.

$\mathrm{O}$ art. 983 traz a previsão de ampla participação dos interessados no deslinde da controvérsia. Este artigo traz um dos principais aspectos que aproxima ao incidente alemão da Musterverfahren, chamado Beiladung, que se destaca por ser uma curiosa modalidade interventiva, prevista em processo administrativo, assemelhada às intervenções de terceiro. Esta ampla possibilidade de participação, dos indivíduos afetados pela suspensão dos processos, bem como do Ministério Público e de outros interessados na resolução da questão jurídica controvertida, apresenta-se útil, pois será partilhado ideias ao debate. 
Concluídas as diligências, o relator do processo designará uma data para a realização do julgamento, ocasião em que as partes da ação originária e o Ministério Público terão sucessivamente trinta (30) minutos para expor suas razões, enquanto que os demais interessados terão o mesmo prazo de trinta (30) minutos, divididos entre eles, sendo exigida inscrição com 2 (dois) dias de antecedência, conforme preceitua o art. 984 do novo Código de Processo Civil.

O $\S 2^{\circ}$ do art. 934 dispõe que o conteúdo do acórdão contenha [...] análise de todos os fundamentos suscitados concernentes à tese jurídica discutida, sejam favoráveis ou contrários". Com o objetivo de diminuir demandas repetitivas, bem como dar tratamento mais uniforme, trata-se de uma homenagem aos artigos 489 e 10 do novo código de processo civil.

Proclamada a decisão do incidente, surge a dificuldade da ampliação dos efeitos do incidente. Observa-se no art. 985, I que os efeitos, em regra, ficarão limitados ao âmbito de competência do tribunal incumbido do julgamento do processo representativo da controvérsia, até pela previsão expressa. Contudo, o art. $987, \S 2^{\circ}$ permite que seja formulado requerimento ao Superior Tribunal de Justiça ou ao Supremo Tribunal Federal, pugnando pela ampliação dos efeitos da decisão, ante a necessidade de se evitar a prolação de pronunciamentos jurisdicionais contraditórios.

O tribunal fixa a tese jurídica, porém é o magistrado de primeiro grau ou a turma julgadora do órgão fracionário do tribunal que a aplica devendo se atentar às particularidades do caso concreto.

Na construção da decisão, deve-se mencionar a possibilidade aplicação do IRDR, bem como fundamentar com base nos demais aspectos jurídicos, tendo em vista o disposto no art. $489 \S 1^{\circ}$ do NCPC.

Segundo o $\S 1^{\circ}$ do artigo 985 "não observada a tese adotada no incidente, caberá reclamação". Já §2॰ dispõe que na ocorrência do incidente "tiver por objeto questão relativa a prestação de serviço concedido, permitido ou autorizado, o resultado do julgamento será comunicado ao órgão, ao ente ou à agencia reguladora competente para fiscalização da efetiva aplicação, por parte dos entes sujeitos a regulação da tese adotada". 
A previsão contida no art. 987 prevê que "do julgamento de mérito caberá recurso extraordinário ou especial, conforme o caso". Pouco importando se a decisão fixou tese jurídica ou se foi oriundo de uma revisão realizada. Em ambos os casos os interessados estarão com as vias recursais abertas para o STF ou STJ. A única exigência que o legislador faz está disposta no $\S 2^{\circ}$ que diz respeito ao enfrentamento do mérito na decisão.

$\mathrm{O} \S 1^{\circ}$ deste artigo traz uma inovação em sua redação ao determinar que os recursos extraordinário e especial terão efeito suspensivo, presumindo-se a repercussão geral de questão constitucional eventualmente discutida, visto que conforme dispõe o artigo $1029, \S 5^{\circ}$ do NCPC os recursos à instância superior terão em regra efeito devolutivo.

Desta forma, vislumbra-se um incidente interlocutório que se desenvolve em um sistema trifásico que gerará a necessidade doutrinária de dimensionamento de como proceder à escolha, aplicando subsidiariamente o critério normativo dos recursos repetitivos (causas que contenham abrangente argumentação e discussão a respeito da questão a ser decidida art. $1036 \$ 6^{\circ}$ ) com a análise da amplitude do contraditório, além da representatividade dos sujeitos do processo das causas escolhidas ${ }^{40}$.

Ainda que este trabalho entenda que o IRDR é uma inovação e que oferecerá mecanismos de resolução de litígios de massa, é preciso conferir uma interpretação que assegure ao instituto sua aplicabilidade conforme os termos da CR/88. Assim, fundamental destacar que este incidente apresenta também, algumas inconstitucionalidades ${ }^{41}$ que violam princípios constitucionais do devido processo legal.

São elas ${ }^{42}$ : (a) violação à independência funcional dos magistrados e à separação funcional dos poderes: a vinculação da tese jurídica aos juízes de hierarquia inferior ao órgão prolator da decisão não está prevista na Constituição da República; (b) violação ao contraditório: ausência do controle judicial da adequação da representatividade como pressuposto fundamental para a eficácia vinculante da decisão de mérito desfavorável aos processos dos litigantes ausentes do incidente processual coletivo; (c) violação ao direito de ação: ausência de previsão do direito de o litigante requerer sua autoexclusão (opt-out) do julgamento coletivo; (d) violação ao sistema de competências da Constituição: a tese jurídica fixada no IRDR pelo TJ ou TRF será aplicada aos processos que tramitem nos juizados especiais do respectivo Estado ou região (art. 985, I, do NCPC). 
Em apertada síntese estas são as disposições que tratam do incidente de resolução de demandas repetitivas, instituto com "natureza de precedente vinculante e projeção erga omne da razão de decidir; tese jurídica geral", que deve ser encarado como uma implementação dialógica do direito jurisprudencial ${ }^{43}$.

Como se sabe o direito brasileiro está muito longe de compreender a relevância do direito jurisprudencial. O NCPC, executado com base em suas premissas, ajuda neste movimento, valorizando o contraditório e incorporando mecanismos para racionalizar a formação e o uso dos precedentes ${ }^{44}$.

Levando-se em conta o que foi observado, conclui-se que o Novo Código de Processo Civil convoca todos os operadores do Direito a observar, analisar e evoluir o sistema jurídico brasileiro, com a aplicação de técnicas como o Incidente de Resolução de Demanda Repetitiva (IRDR).

\section{CONSIDERAÇÕES FINAIS}

Inegavelmente, com a promulgação da Constituição da República de 1988, foi trazida e afirmada uma interessante proposta social de Modelo de Estado Constitucional. Em seu artigo $1^{\circ}$, a terminologia "Estado Democrático de Direito" é constituída por fundamentos sociais embasados em princípios, que deve aparecer como uma espécie de qualidade, de característica, de paradigma jurídico.

\footnotetext{
${ }^{40}$ NUNES, Dierle José Coelho; THEODORO JR, Humberto; BAHIA, Alexandre G. M. F.; PEDRON, Flávio Quinaud. Novo CPC: Fundamentos e sistematização - Lei 13.015, de 16.03.2015. 2. ed. Rio de Janeiro: Gen/Forense, 2015. v. 1. p.388.

${ }^{41}$ CAVALCANTI, Marcos. Incidente de Resolução de Demanda Repetitiva e Ações Coletivas. Editora Juspodivm, 2015, p.587.

${ }^{42}$ CAVALCANTI, Marcos. Incidente de Resolução de Demanda Repetitiva e Ações Coletivas. Editora Juspodivm, 2015, p.588.

${ }^{43}$ Ibidem, p. 379.

${ }^{44}$ Ibidem, p. 393.
} 
No entanto, devido ao amplo acesso à jurisdição, a sociedade brasileira repercute uma litigiosidade massificada, com inúmeras demandas semelhantes ajuizadas pelos mais diversos litigantes.

$\mathrm{Na}$ tentativa de lidar com os litígios de massa, iniciou-se uma fase de reformas processuais. Exemplo disso foi o movimento acadêmico pela defesa do novo sistema processo coletivo comum, através de propostas para criação do Código Brasileiro de Direitos Coletivos e de uma nova Lei de Ação Civil Pública.

O estudo dos mecanismos de resolução de conflitos de massa em nosso país foi realizado pelo desenvolvimento da tutela jurisdicional coletiva já existente no direito alienígena, especialmente porque as ações coletivas brasileiras surgiram como derivação das class actions norte-americanas.

Como as demandas de massa, repetitivas, que nada mais são do que processos individuais e/ou coletivos que, em larga escala, repetem-se no Poder Judiciário foram apresentados pela legislação vários institutos, quais sejam, as Súmulas Vinculantes, as Súmulas impeditivas de recurso e a Repercussão geral.

No IRDR, poderão se manifestar várias pessoas, com diversas teses relacionadas à matéria litigiosa, e, ao final o tribunal competente fixará tese jurídica será aplicada obrigatoriamente a todas as ações individuais ou coletivas.

Deste modo, verifica-se que toda inovação legislativa deve respeito à Carta Magna e seus princípios cardeais. Observa-se ainda que as garantias fundamentais são a positivação de direitos difusos e de direitos coletivos não cabendo ao Poder Legislativo a disponibilidade dos mesmos para a promulgação de leis que visem efetivar algumas garantias fundamentais em preterição de outras. Já que, posicionamento contrário faria com que passássemos a ponderar até que ponto as funções representativa e legislativa delegada pelo povo a alguns poucos representantes podem conferir força necessária para sopesar e tender à preterição de garantias fundamentais em face de outras.

Portanto, levando-se em conta o que foi observado, conclui-se que o Novo Código de Processo Civil convoca todos os operadores do Direito a observar, analisar e evoluir o sistema 
jurídico brasileiro, com a aplicação de técnicas como o Incidente de Resolução de Demanda Repetitiva (IRDR).

\section{REFERÊNCIAS BIBLIOGRÁFICAS}

AMARAL, Guilherme Rizzo. Efetividade, segurança, massificação e a proposta de um "incidente de resolução de demandas repetitivas". In. WAMBIER, Teresa Arruda Alvim (org). Revista de Processo, v. 36, n. 196. São Paulo: Editora Revista dos Tribunais, 2011.

Art. $2^{\circ}$ e $3^{\circ}$ da Lei 11.417, de 19 de Dezembro de 2006. Diário Oficial da União, 20 dez. 2006.

DEL NEGRI, André. Controle de Constitucionalidade no Processo Legislativo (2 $2^{\mathrm{a}}$ edição). $2^{\mathrm{a}}$. ed. Belo Horizonte: Editora Fórum, 2008. v. 1. p.34-35.

BRASIL. Constituição (1988). Constituição da República Federativa do Brasil. Brasília, DF: Senado, 1988.

BRASIL. Lei 5.869, de 11 de janeiro de 1973. Institui o Código de Processo Civil. Diário Oficial da União, Brasília, 17 jan. 1973.

CABRAL, Antonio do Passo. O novo Procedimento-Modelo (Musterverfahren) alemão: uma alternativa às ações coletivas. Revista de Processo, v. 147, p. 40-55, 2007.

CAPPELLETTI, Mauro; GARTH, Bryant. Acesso à Justiça. Trad. Ellen Gracie Northfleet. Porto Alegre: Sergio Antonio Fabris, 1988.

CASAGRANDE, Érico Vinícius Prado. Repercussão Geral no Recurso Extraordinário e Garantia Fundamental da Ampla Defesa: Estudo do novo requisito de admissibilidade do recurso extraordinário sob a perspectiva de uma teoria do direito democrático. 2008., p.115. Dissertação (Mestrado em Direito Processual) - Pontifícia Universidade Católica, Belo Horizonte.

CAVALCANTI, Marcos. Incidente de Resolução de Demanda Repetitiva e Ações Coletivas. Editora Juspodivm, 2015, p.47. 
DANTAS, Bruno. Repercussão Geral: Perspectiva histórica, dogmática e de direito comparado: Questões Processuais. São Paulo: Revista dos Tribunais, 2008. p. 257.

DEL NEGRI, André. Controle de Constitucionalidade no Processo Legislativo ( $2^{\mathrm{a}}$ edição). 2a . ed. Belo Horizonte: Editora Fórum, 2008. v. 1. p.34-35.

FALEIROS, Thaísa Haber. Tutela judicial efetiva como direito. Revista Jus Navigandi, Teresina, ano 7, n. 54, 1 fev. 2002. Disponível em:<http://jus.com.br/artigos/2682>. Acesso em: 4 nov. 2015.

FUX, Luiz. O Novo Processo Civil. In. FUX, Luiz (org.). O novo processo civil brasileiro Direito em expectativa. Rio de Janeiro: Forense, 2011, p. 4 - 6.

GAROUPA, Nuno. MALDONADO, Maria A. The Judiciary in Political Transitions: The Critical Role of U.S Constitucionalism in Latin America. Cardozo J. Int l \& Comp L., v.19.n.3, July 2010, p.526.

LEAL, Márcio Flávio Mafra. Curso de Processo Civil comparado Brasil-Alemanha. In: Revista de Processo. Säo Paulo: RT, n.178, dez. 2009, p.230.

Lei 13.105/2015, de 16 de Março de 2015. (2015,16 março). Institui o novo Código de Processo Civil. Diário Oficial da União.

MAURO e GARTH, Bryan. Acesso à justiça. Tradução de Ellen Gracie Northfleet. Porto Alegre: Sergio Antonio Fabris, 2002.p.3

NUNES, Dierle José Coelho; THEODORO JR, Humberto; BAHIA, Alexandre G. M. F.; PEDRON, Flávio Quinaud. Novo CPC: Fundamentos e sistematização - Lei 13.015, de 16.03.2015. 2. ed. Rio de Janeiro: Gen/Forense, 2015. v. 1. p.370-393.

PENEDO, Felipe Orletti. A progressão do ordenamento jurídico brasileiro no curso do Direito Transindividual: A criação do instituto de Resolução de Demandas Repetitivas. Disponível em <http://www.revistaalumni.com.br/index.php/ALUMNI/article/view/3>. Acesso em $04 \mathrm{de}$ nov. de 2015.

THEODORO JÚNIOR, Humberto. Curso de direito processual civil. 39. ed. Rio de Janeiro: Forense, 2005., 3 v.,p.660. 